\title{
Correction to: Morphological and taxonomic demarcation of Brachionus asplanchnoidis Charin within the Brachionus plicatilis cryptic species complex (Rotifera, Monogononta)
}

\author{
Evangelia Michaloudi $(\mathbb{D} \cdot$ Scott Mills $\cdot$ Spiros Papakostas • Claus-Peter Stelzer • \\ Alexander Triantafyllidis • Ilias Kappas - Kalliopi Vasileiadou • \\ Konstantinos Proios • Theodore John Abatzopoulos
}

Published online: 2 October 2019

(C) Springer Nature Switzerland AG 2019

\section{Correction to: Hydrobiologia (2017) 796:19-37 https://doi.org/10.1007/s10750-016-2924-2}

The authors of the original publication recognized that, for three of the clones (MAN-L5, LFL2, KOR), the data of two of the raw morphometric measurements contained in Supplementary Material 2 of the article were flipped (the distance between the anterior tips of the 3rd dorsal spines ' $b$ ' and the width of the lorica 'c'). The corrected Supplementary material 2 is

The original article can be found online at https:// doi.org/10.1007/s10750-016-2924-2.

Electronic supplementary material The online version of this article (https://doi.org/10.1007/s10750-019-04050-x) contains supplementary material, which is available to authorized users.

E. Michaloudi $(\bowtie) \cdot K$. Proios

Department of Zoology, Aristotle University of

Thessaloniki, 54124 Thessaloníki, Greece

e-mail: tholi@bio.auth.gr

S. Mills

James Cook University, 1 James Cook Drive,

Townsville 4811, Australia

S. Papakostas

Division of Genetics and Physiology, Department of

Biology, University of Turku, 20014 Turku, Finland

C.-P. Stelzer

Research Institute for Limnology, University of

Innsbruck, 5310 Mondsee, Austria provided here. As a consequence, the principal components analysis (PCA) and discriminant analysis (DA) were repeated, and the corrected version of Fig. 3, Tables 4, 5, 6 and 7 are also provided here.

PCA explains a similar amount of the observed variation (PC1 71.14\%, PC2 8.89\%) and still clearly separates the clones of $B$. asplanchnoidis from the rest of the members of the $\mathrm{L}$ clade, revealing however a great degree of morphometric variability within the $B$. asplanchnoidis members (Fig. 3A). DA performed on the phylogenetically identified species also clearly separates B. asplanchnoidis from the rest of the species (Fig. 3B). Table 4 shows the results of the discriminant analysis where the classification factor was the four species of the $\mathrm{L}$ clade. Classification Functions 1 and 2 accounted for a similar amount of the total variance, $78.3 \%$ and $16.2 \%$, respectively,
A. Triantafyllidis - I. Kappas - K. Vasileiadou ·
T. J. Abatzopoulos
Department of Genetics, Development \& Molecular
Biology, Aristotle University of Thessaloniki,
54124 Thessaloníki, Greece 

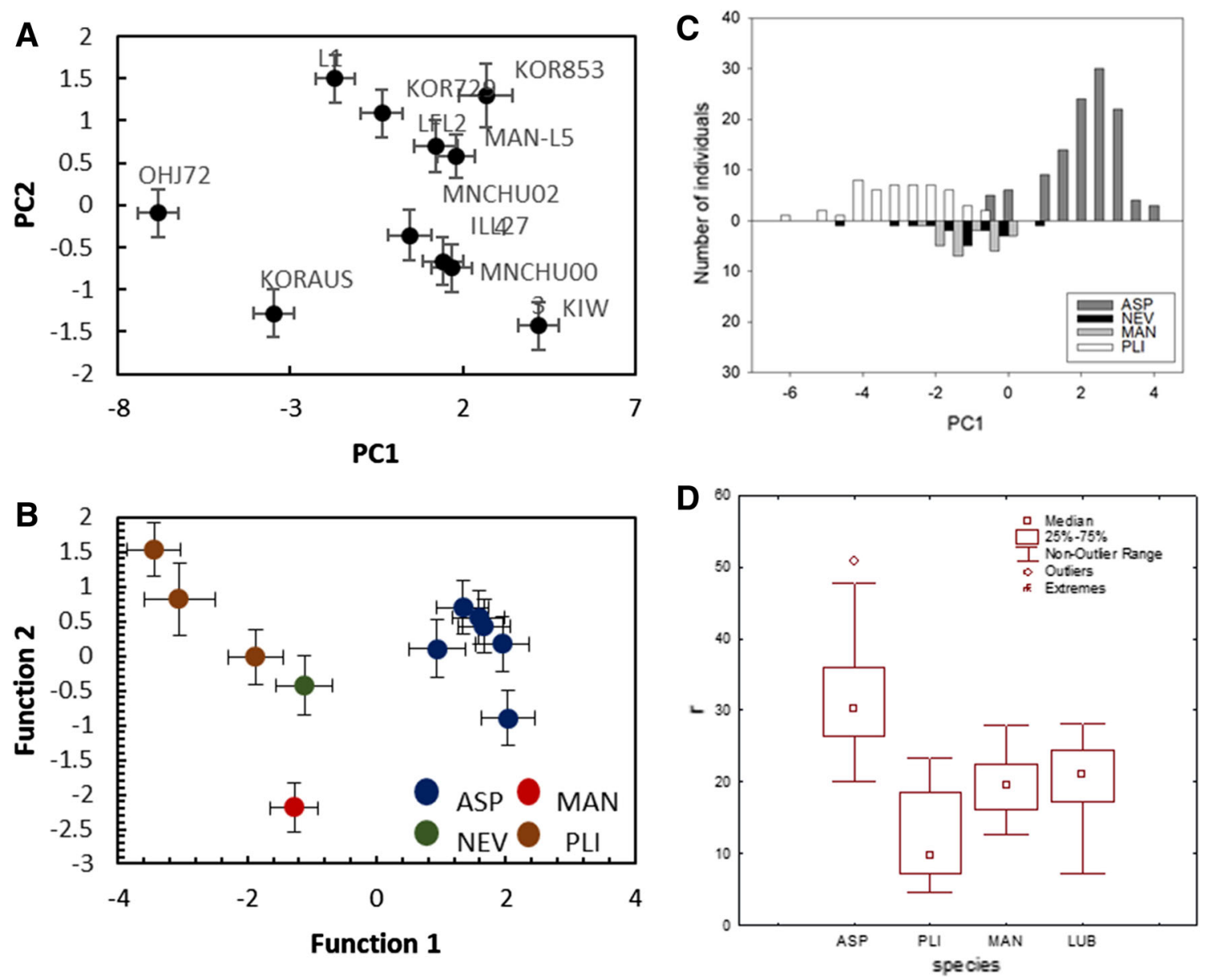

Fig. 3 Analysis of the association between species delimitation and morphometry. A Representation of sample score averages of each of the studied clones along the first two axes of the principal components analysis (PC1 explained $71.14 \%$ and $\mathrm{PC} 2$ explained $8.89 \%$ of the recorded variation) performed on the morphometric data. Error bars represent variation between individuals of the same clone (twice the standard error of the mean). B Scatterplot showing the discrimination of species groups based on the canonical discriminant functions of the discriminant analysis performed on all measured individuals.

revealing mainly two groups (Wilks' Lambda $=$ 0.454, $\chi^{2}=158.61, d f=14, P<0.001$ ) (Fig. 3B). The variables weighting the most in the classification function 1 were the width of the medial sinus of the anteroventral margin $(r)$ and the width of the lorica (c) (see correlation coefficient in Table 4). Crossvalidation of the individuals' classification based on the classification functions (Table 5) of the discriminant analysis correctly identified $96.6 \%$ B. asplanchnoidis individuals. Still, for the two groups, i.e., one group B. asplanchnoidis clones and the other group $B$.
Error bars represent variation between individuals of the same clone (twice the standard error of the mean). C Distribution of the number of individuals of Brachionus asplanchnoidis and the rest of the $\mathrm{L}$ group members along the discriminant axis obtained from morphometric data. The bars shown under the $x$ axis do not represent negative values. D Box-and-whisker plot of $\mathrm{r}$ (width of the medial sinus of the anteroventral margin) for the four species ASP, Brachionus asplanchnoidis; PLI, B. plicatilis; MAN, B. manjavacas; NEV, B. 'Nevada'

plicatilis, B. manjavacas, and B. 'Nevada' clones, identified in the discriminant analysis, some overlap was recorded of the scores of the discriminant functions (Fig. 3C). All measurements (Supplementary Material Table 2) covered a wide range of values within each species and exhibited great overlap (Table 6), while most of them differed significantly between species (Table 7). From the morphological analysis, the differences between $B$. asplanchnoidis and the rest of the representatives of the $\mathrm{L}$ clade concern the anteroventral margin which is more 
Table 4 Stepwise discriminant analysis of the Brachionus body measurements

\begin{tabular}{lcccc}
\hline Measurement & Function 1 & & \multicolumn{2}{c}{ Function 2} \\
\cline { 2 - 4 } & Coefficient & Correlation & Coefficient & Correlation \\
\hline$a$ & -0.505 & 0.050 & -2.321 & 0.184 \\
$b$ & 0.110 & 0.084 & 0.901 & 0.316 \\
$c$ & 1.687 & 0.047 & 1.761 & 0.243 \\
$g$ & 0.146 & 0.059 & 0.119 & 0.395 \\
$l$ & -0.777 & -0.064 & 0.319 & 0.141 \\
$o$ & -0.242 & 0.039 & -1.257 & -0.037 \\
$p$ & -0.855 & -0.170 & -0.471 & -0.240 \\
$r$ & 1.066 & 0.697 & 0.749 & 16.2 \\
Eigenvalue & 3.631 & & & \\
\% Variance & 78.3 & & 0.316 & \\
\hline
\end{tabular}

Values of the first two canonical functions are shown. Coefficient: standardized coefficient for the canonical discriminant function. Correlation: pooled within group correlation coefficient between the body measurement and the canonical discriminant function

Table 5 Classification functions of the stepwise discriminant analysis
ASP, Brachionus asplanchnoidis; PLI, B. plicatilis; MAN, $B$. manjavacas; $\mathrm{NEV}, B$. 'Nevada'

\begin{tabular}{lrrrr}
\hline Measurement & \multicolumn{1}{l}{ ASP } & \multicolumn{1}{l}{ PLI } & \multicolumn{1}{l}{ MAN } & \multicolumn{1}{l}{ NEV } \\
\hline$a$ & 357.54 & 369.27 & 437.82 & 348.83 \\
$b$ & 1792.56 & 1790.11 & 1742.75 & 1817.13 \\
$c$ & 231.63 & 157.35 & 123.34 & 188.62 \\
$g$ & -153.29 & -153.49 & -181.89 & -156.48 \\
$l$ & -446.51 & -413.53 & -428.56 & -414.99 \\
$o$ & -836.68 & -817.20 & -829.73 & -867.98 \\
$p$ & -185.40 & -149.70 & -120.05 & -143.86 \\
$r$ & 56.69 & 17.98 & 41.20 & 37.33 \\
Constant & -1449.36 & -1383.15 & -1377.82 & -1411.74 \\
\hline
\end{tabular}

pronounced in the case of $B$. plicatilis (Fig. 3D). In $B$. asplanchnoidis, the medial sinus is much deeper and wider compared to B. plicatilis ( $r$ range $20-51 \mu \mathrm{m}$ and 5-23 $\mu \mathrm{m}$, respectively).

The main conclusions of this study remain the same. Brachionus asplanchnoidis differs compared to the rest of the representatives of the $\mathrm{L}$ clade of the $B$. plicatilis complex based on the medial sinus of the anteroventral margin, which is more pronounced in the case of, e.g., B. plicatilis (Fig. 3D). In B. asplanchnoidis, the medial sinus is much deeper and wider ( $r$ range $20-51 \mu \mathrm{m}$ ) compared to B. plicatilis ( $r$ range 5-23 $\mu \mathrm{m})$. Furthermore, the structured orange peellike surface is more closely spaced and less pronounced in B. asplanchnoidis compared to B. plicatilis (Fig. 5B, C). Nevertheless, as already pointed out by Fontaneto et al. (2007), the observed morphological differences are greater among the size clades of the $B$. 
Table 6 Measurements (in $\mu \mathrm{m})$ (range, mean, St. Error) of the dimensions of the individuals that have been used for the morphometric analysis

\begin{tabular}{|c|c|c|c|c|c|c|c|c|}
\hline \multirow[t]{2}{*}{ Measurement } & \multicolumn{4}{|c|}{ B. asplanchnoidis } & \multicolumn{4}{|c|}{ B. plicatilis } \\
\hline & Min & Max & Mean & SE & Min & Max & Mean & SE \\
\hline$a$ & 185 & 510 & 295.12 & 8.14 & 219 & 374 & 283.63 & 6.38 \\
\hline$b$ & 82 & 166 & 126.12 & 1.85 & 98 & 143 & 122.36 & 1.72 \\
\hline$c$ & 138 & 342 & 206.58 & 4.82 & 158 & 282 & 203.62 & 5.49 \\
\hline$e$ & 12 & 46 & 26.64 & 0.75 & 21 & 34 & 27.33 & 0.42 \\
\hline$g$ & 6 & 28 & 14.42 & 0.45 & 10 & 19 & 13.74 & 0.31 \\
\hline$j$ & 17 & 51 & 31.11 & 0.82 & 24 & 37 & 30.35 & 0.51 \\
\hline$i$ & 89 & 175 & 130.88 & 2.12 & 102 & 159 & 132.44 & 2.13 \\
\hline$k$ & 10 & 31 & 19.41 & 0.43 & 16 & 28 & 21.48 & 0.43 \\
\hline$l$ & 12 & 42 & 23.86 & 0.67 & 17 & 33 & 25.42 & 0.59 \\
\hline$m$ & 53 & 119 & 80.02 & 1.31 & 55 & 90 & 76.79 & 1.22 \\
\hline$n$ & 13 & 38 & 24.41 & 0.48 & 17 & 34 & 25.17 & 0.61 \\
\hline$o$ & 21 & 57 & 34.17 & 0.70 & 25 & 44 & 34.29 & 0.71 \\
\hline$p$ & 17 & 51 & 33.37 & 0.70 & 29 & 47 & 37.66 & 0.73 \\
\hline$q$ & 24 & 75 & 34.75 & 0.68 & 21 & 40 & 30.06 & 0.64 \\
\hline$r$ & 20 & 51 & 31.12 & 0.64 & 5 & 23 & 12.47 & 0.86 \\
\hline \multirow[t]{2}{*}{ Measurement } & \multicolumn{4}{|c|}{ B. manjavacas } & \multicolumn{4}{|c|}{ B. 'Nevada' } \\
\hline & Min & Max & Mean & SE & Min & Max & Mean & SE \\
\hline$a$ & 216 & 288 & 256.28 & 3.90 & 192 & 266 & 241.27 & 5.96 \\
\hline$b$ & 91 & 122 & 109.37 & 1.75 & 99 & 132 & 116.83 & 2.31 \\
\hline$c$ & 146 & 202 & 177.67 & 2.62 & 139 & 200 & 175.08 & 4.28 \\
\hline$e$ & 16 & 29 & 21.74 & 0.52 & 17 & 31 & 23.66 & 0.87 \\
\hline$g$ & 7 & 12 & 10.04 & 0.28 & 9 & 18 & 12.83 & 0.53 \\
\hline$j$ & 20 & 32 & 25.56 & 0.61 & 20 & 33 & 26.24 & 0.73 \\
\hline$i$ & 99 & 138 & 125.09 & 1.91 & 114 & 140 & 127.19 & 2.35 \\
\hline$k$ & 13 & 21 & 17.64 & 0.45 & 16 & 24 & 20.20 & 0.63 \\
\hline$l$ & 13 & 26 & 22.42 & 0.62 & 17 & 27 & 23.10 & 0.79 \\
\hline$m$ & 56 & 82 & 68.17 & 1.41 & 57 & 92 & 70.59 & 2.18 \\
\hline$n$ & 15 & 28 & 23.90 & 0.57 & 20 & 31 & 24.86 & 0.67 \\
\hline$o$ & 25 & 35 & 29.38 & 0.63 & 24 & 36 & 28.02 & 0.80 \\
\hline$p$ & 26 & 41 & 36.37 & 0.66 & 32 & 43 & 36.62 & 0.80 \\
\hline$q$ & 23 & 34 & 28.85 & 0.59 & 24 & 32 & 29.06 & 0.57 \\
\hline$r$ & 13 & 28 & 19.69 & 0.93 & 7 & 28 & 20.25 & 1.28 \\
\hline
\end{tabular}


Table 7 Results of ANOVA and post hoc Fisher LSD test for differences in lorica measurements identified as discriminating traits between the four species of Brachionus plicatilis cryptic species complex

\begin{tabular}{|c|c|c|c|c|c|c|c|}
\hline \multirow[t]{2}{*}{ Measurement } & \multicolumn{4}{|c|}{ Fisher LSD test } & \multicolumn{3}{|c|}{ ANOVA } \\
\hline & ASP & MAN & NEV & PLI & $d f$ & $F$ & $P$ \\
\hline$a$ & A & B & B & A & 3 & 13.31 & $<0.001$ \\
\hline$b$ & A & B & $\mathrm{C}$ & A & 3 & 16.59 & $<0.001$ \\
\hline$c$ & A & B & B & A & 3 & 13.18 & $<0.001$ \\
\hline$e$ & A & B & $\mathrm{C}$ & $\mathrm{D}$ & 3 & 22.04 & $<0.001$ \\
\hline$g$ & A & B & $\mathrm{C}$ & A C & 3 & 26.56 & $<0.001$ \\
\hline$j$ & A & B & B & A & 3 & 19.34 & $<0.001$ \\
\hline$i$ & A & A B & A & A C & 3 & 2.85 & $<0.001$ \\
\hline$k$ & A & B & $\mathrm{C}$ & $\mathrm{D}$ & 3 & 20.65 & $<0.001$ \\
\hline$l$ & A & A & A & $\mathrm{D}$ & 3 & 8.06 & $<0.001$ \\
\hline$m$ & A & B & $\mathrm{B}$ & $\mathrm{D}$ & 3 & 19.07 & $<0.001$ \\
\hline$n$ & A & A & A & A & 3 & 1.73 & $<0.001$ \\
\hline$o$ & A & B & B & A & 3 & 27.81 & $<0.001$ \\
\hline$p$ & A & B & B & B & 3 & 18.11 & $<0.001$ \\
\hline$q$ & A & B & B & B & 3 & 26.01 & $<0.001$ \\
\hline$r$ & A & B & B & $\mathrm{D}$ & 3 & 182.71 & $<0.001$ \\
\hline
\end{tabular}

plicatilis cryptic species complex than within each size group.

\section{Reference}

Fontaneto, D., I. Giordani, G. Melone \& M. Serra, 2007. Disentangling the morphological stasis in two rotifer species of the Brachionus plicatilis species complex. Hydrobiologia 583: 297-307.

Publisher's Note Springer Nature remains neutral with regard to jurisdictional claims in published maps and institutional affiliations. 